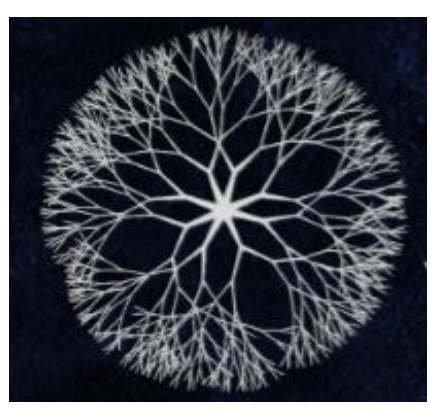

Khronos, Revista de História da Ciência

ISSN 2447-2158 - no 4, agosto 2017

DOSSIÊ - História das Ciências e seu papel na educação básica brasileira

\title{
História da Ciência no Ensino Médio: caminhos para uma interdisciplinaridade possível
}

\author{
Gisela Tolaine Massetto de Aquino \\ Doutora em História Social - USP - FFLCH \\ gtm.aquino@gmail.com
}

Recebido em 26/05/2017. Aprovado em 29/06/2017.

Como citar este artigo: Aquino, Gisela T. M.; "História da Ciência no Ensino Médio: caminhos para uma interdisciplinaridade possível”. Khronos, Revista de História da Ciência, nª, p. 14-31. 2017. Disponível em $<$ http://revistas.usp.br/khronos $>$. Acesso em dd/mm/aaaa.

Resumo: Ainda hoje a ciência é vista pela maioria dos alunos matriculados no ensino médio brasileiro como um conjunto de dogmas resultante de processos de observação e desvinculada do seu contexto social. Este artigo pretende discutir esta situação e apresentar propostas no sentido de modificar esta realidade. O caminho sugerido está na exploração de conteúdos de história da ciência, trabalhado por professores de ciências humanas e de ciência da natureza e matemática, de forma conjunta e simultânea. História da ciência deve ser entendida como algo que é produzido por seres humanos inseridos num contexto histórico e que pode atender as mais diferentes aspirações tornando-se essenciais para a formação de um indivíduo crítico que saiba avaliar corretamente as implicações sociais do uso da ciência e da tecnologia.

Palavras-chave: História da Ciência, Ensino Médio, Interdisciplinaridade.

\section{History of Science in High School: ways for possible interdisciplinarity}

\begin{abstract}
Nowadays, Science is perceived by most of the students enrolled in the Brazilian high school system as a set of dogmas resulted from observation processes and disconnected from its social context. This article aims to discuss this issue and present proposals to modify this reality. The suggested pathway explores the content of the history of science, worked by teachers of human sciences, natural science and mathematics, simultaneously. History of science must be comprehended as being produced by human beings inserted in a historical context, and that can address diverse aspirations. It becomes essential for the formation of a critic who would know how to correctly evaluate the social implications of the use of science and technology.
\end{abstract}

Keywords: History of Science, High School, interdisciplinarity. 
Ensinar história, em geral, consiste em uma tarefa bastante complexa. O universo escolar está permeado por ideias preconcebidas sobre a "necessidade" (ou não...) de se estudar história. E pior, de como devemos estudá-la. Nesse contexto, alguns docentes de áreas diferentes afirmam que ensinar, na área de humanidades, é "fácil" porque basta que o professor "conte o que aconteceu", a aula está dada. É comum afirmar-se que professores de história e geografia são "aquelas pessoas simpáticas" que ficam para sempre guardados na memória dos estudantes. Também existe um senso comum que afirma serem essas disciplinas bastante simples e por isso, normalmente caem no gosto dos jovens. Porém, entre os alunos a "fama" da história é diferente. Esbarra-se em ideias comuns tais como "não vale a pena estudar o que já passou", "por que eu preciso saber sobre esse cara se quando eu nasci ele já havia morrido?" ou "não há a necessidade de se decorar fatos que aconteceram no passado". Mas, certamente não é nada daquilo que a maioria pensa: história é muito mais. Precisa-se mostrar aos estudantes (e, muitas vezes, aos colegas professores) que se vive a história cotidianamente, que todos somos indivíduos históricos. A história, como disciplina, possibilita que se estude os problemas contemporâneos nos mais diferentes contextos. Nos possibilita refletir, buscar soluções. Como nos mostra Le Goff1, "a ciência do tempo, a história é uma componente indispensável de toda a atividade temporal”.

Por esses e outros motivos é necessário buscar outras formas de trazer essa consciência histórica aos estudantes. Acreditamos que através da pesquisa em outras ciências encontremos caminhos e estratégias para tornar essa expectativa uma realidade. Trabalhando com a ideia da não fragmentação do conhecimento podemos torná-lo muito mais acessível aos nossos alunos.

Foi nos anos de 1990 que essas concepções de educação começaram a parecer mais concretas $^{2}$. A ideia de trabalhar o conteúdo através de projetos, da interdisciplinaridade - da não fragmentação do processo de ensino-aprendizagem - fazia muito sentido. Acreditava-se que quanto mais ampliássemos a visão do aluno, sem a fragmentação disciplinar, mais fácil seria para que ele compreendesse o todo. Isto quer dizer que não podemos aceitar que um estudante pode "ser bom em história e ter dificuldade em literatura" (frase que se escuta com certa frequência em salas de professores, como se aluno tivesse um compartimento para aprender cada uma das disciplinas). Portanto a busca da integração desses conteúdos seria fundamental para que houvesse uma real modificação na forma de se enxergar a educação, observando assim, as necessidades e as consequências delas, na formação do indivíduo.

Com a publicação dos Parâmetros Curriculares Nacionais $(\mathrm{PCN})^{3}$, a ideia de relacionar a história com as outras disciplinas (ligadas às ciências humanas) permitiu a junção e o aprofundamento de muitos temas vistos nos ensino fundamental e médio, mostrando aspectos mais abrangentes da vida em sociedade e a importância do próprio indivíduo, nas modificações do processo histórico, complementando o entendimento das relações entre a necessidade (produto de uma história fruto de uma ação determinada pela sociedade) e a liberdade (ação do

${ }^{1}$ LE GOFF, J. História e Memória. Campinas: Unicamp, 1996, p.23.

${ }^{2}$ O Brasil viveu, na década de 1990, um contexto de reforma educacional. O principal indicador que nos mostram a intencionalidade e implementação de mudanças foi a Lei de Diretrizes e Bases da Educação de 1996. Podemos ainda mencionar as ações do Ministério da Educação que tomaram por objeto as mudanças curriculares e a organização geral da escola, tais como os Parâmetros Curriculares Nacionais (1998), o Sistema de Avaliação da Educação Básica - Saeb (1991) e as Diretrizes Curriculares Nacionais propostas pelo Conselho Nacional de Educação.

3 Os Parâmetros Curriculares Nacionais (PCN's) são a referência básica para a elaboração das matrizes de referência. Os PCN's foram elaborados para difundir os princípios da reforma curricular e orientar os professores na busca de novas abordagens e metodologias. Eles traçam um perfil para o currículo, apoiado em competências básicas para a inserção dos jovens na vida adulta; orientam os professores quanto ao significado do conhecimento escolar quando contextualizado e quanto à interdisciplinaridade, incentivando o raciocínio e a capacidade de aprender. (http://portal.inep.gov.br/web/saeb/parametroscurriculares-nacionais, acesso em 05 de maio de 2014) 
indivíduo que é sujeito da história). Apenas essa perspectiva já nos mostra o nível de importância deste tipo de abordagem para a formação integral do indivíduo.

Pensando dentro deste formato, o trabalho desenvolvido junto aos estudantes, deve facilitar o estabelecimento das relações entre as diferentes disciplinas e áreas do conhecimento. Isso é ainda mais visível nas análises realizadas com estudantes de ensino médio, pois o conhecimento, naquele nível passa a ser ainda mais fragmentado. Inicialmente, nos parece mais simples propor trabalhos dentro de uma mesma área como, por exemplo, das humanidades. Isso facilita o trabalho do professor e a compreensão de conceitos pelos estudantes ${ }^{4}$. Geralmente, uma visão multidisciplinar é facilmente abraçada pelo corpo discente, o que influencia a aceitação e a integração do corpo docente. É comum que os alunos consigam enxergar a relação existente entre as disciplinas de uma mesma área. Podemos exemplificar com a grande variedade de trabalhos desenvolvidos entre história e geografia, história e literatura, história e arte, entre outros. Para os professores envolvidos esta é uma postura motivadora. Elaborar aulas com a participação dos colegas sempre é mais motivador... Embora a divisão dos horários (dentro do currículo escolar) fragmente o conhecimento, os professores e alunos se encarregam de reconstruir o que vem "aos pedaços". O resultado aparece rápido. Em geral, esses estudantes têm bom aproveitamento, em humanidades, nas provas e exames internos (da escola) e nos exames externos (tais como vestibulares e mais recentemente o ENEM - Exame Nacional do Ensino Médio). Mais do que ter sucesso em exames, nota-se que ter a noção do todo ajuda esses alunos na resolução de problemas e na compreensão de conceitos (mais do que simplesmente compreender determinado conteúdo). Isto é, baseados na experiência de ter a visão do todo, lançam mão do que têm para tentar solucionar outros problemas de outras áreas. Os resultados, em geral, são tão bons que podemos tentar usar a mesma estratégia para aproximar áreas diferentes do conhecimento.

Embora queiramos acreditar que a convivência entre todas as disciplinas (e seus respectivos professores) seja pacífica e que todos tenham a mesma responsabilidade e importância na formação dos estudantes, isso não é real. Há uma ordem tácita entre professores, direção que chega até o aluno. Nas escolas de ensino médio (independentemente de serem públicas ou privadas), há uma grande separação entre as chamadas "disciplinas duras", (matemática, física, química e, muitas vezes, biologia) e as outras disciplinas. Tem-se uma visão de que estas "disciplinas duras" seriam muito mais difíceis e exigiriam mais dos estudantes. Geralmente são as matérias que mais têm alunos em processos de recuperação e também aquelas que mais reprovam. No imaginário escolar aquelas são disciplinas que merecem mais respeito, merecem ser estudadas, deixando-se de lado outras consideradas mais fáceis (em geral dizem ser matérias "decorativas").

Como os trabalhos com a aproximação das humanidades tem sido realizado em diferentes instituições de ensino e com êxito parece-me interessante estendê-lo para as disciplinas "duras". Aproximar ciências humanas da matemática e das ciências da natureza deveria ser considerada uma boa estratégia de trabalho ${ }^{5}$. Tanto para o ensino da matemática e das ciências da natureza como para a história.

\footnotetext{
${ }^{4}$ Durante mais de cinco anos (desde o início de 2007 até fins de 2013) coordenei a área de humanidades no Ensino Médio, na região Metropolitana de São Paulo. A atividade buscava relacionar os conteúdos trabalhados em história, geografia, filosofia, sociologia, história da arte, literatura e atualidades. Os professores e faziam menção sobre isso em suas aulas. Os estudantes conseguiam, desta forma, ver o que estava sendo discutido sob o "olhar" de várias disciplinas. A ação resultava numa riqueza de informações facilitando a compreensão de fatos e de conceitos. Com esta atitude conseguíamos "reunir" o que lhes havia sido apresentado de forma fragmentada. Como resultado passamos a notar que houve uma facilitação no processo de apropriação do conhecimento e, mais do que isso, de compreensão geral de grandes temas.

${ }^{5}$ Esta temática - aproximação de dois universos tão diferentes, humanidades e ciência - não é nova. Em 1959, numa famosa conferência, o cientista e escritor britânico C. P. Snow observou e "denunciou" um cisma na vida intelectual do mundo ocidental. $\mathrm{Na}$ análise feita por ele, uma distância cada vez maior
} 
Além do mais, vivemos um momento característico, em que os avanços científicos, técnicos e sociológicos estão cada vez mais interligados. Há mais de três séculos, o conhecimento científico vem provando suas virtudes de verificação e de descoberta em relação a todos os outros modos de conhecimento. Apenas através do conhecimento vivo é que se pode guiar a sociedade na grande aventura da descoberta do universo, da vida e do homem ${ }^{6}$.

Ensinar, de modo geral, neste universo da tecnologia, das inovações científicas e da informação cada vez mais rápida passa a ser um desafio àqueles que se dispõem a tentar.

Ao fazermos uma rápida leitura da organização de nossa sociedade, podemos observar que o desenvolvimento da ciência e da tecnologia tem trazido grandes transformações? ${ }^{7}$. O reflexo destas mudanças é bem marcante no que diz respeito aos níveis econômicos, político e social. Estas mudanças precisam ser analisadas com mais profundidade pela própria sociedade. Desta forma, torna-se cada vez mais necessário que a população possa, além de ter acesso às informações sobre o desenvolvimento científico-tecnológico, ter também condições de avaliar e participar das decisões que venham a atingir o meio onde vive ${ }^{8}$. Neste sentido faz-se necessário que o assunto possa ser introduzido e discutido na escola.

Desde a década de 1960 a ideia de inserir o ensino de ciência e tecnologia no currículo do ensino regular vem sendo discutida. Em países do hemisfério norte o movimento denominado "Ciência, Tecnologia e Sociedade" tem trabalhado a discussão de temas que envolvem a ciência e a tecnologia no âmbito da educação formal'. No Brasil esta ideia constitui-se ainda como algo em emergência. Existem algumas iniciativas, ainda tímidas, mas não traduzidas em programas institucionais. Através de rápida revisão bibliográfica, constata-se que o discurso sobre o tema não é consensual, levando-se em conta objetivos, conteúdos, abrangência e modalidades de implementação $0^{10}$.

Nesse campo de investigação percebemos que existe a necessidade de renovação na estrutura curricular dos conteúdos, de forma a colocar ciência e tecnologia em novas concepções vinculadas ao contexto social. De acordo com Medina e Sanmartín ${ }^{11}$, quando se pretende incluir o enfoque no contexto educacional é importante que alguns objetivos sejam seguidos:

1. Questionar as formas pré-existentes de estudar e atuar sobre a natureza, que devem ser sempre objeto de reflexão. Sua legitimação só pode ser feita por meio do sistema educativo, pois assim é possível contextualizar permanentemente os conhecimentos em função das necessidades da sociedade.

separava a cultura dos cientistas naturais, por um lado, e a dos intelectuais de humanidades, por outro. Com a diminuição progressiva das referências comuns, o diálogo entre os representantes das duas culturas foi se tornando inviável. Mais do que pensar sobre esta separação, Snow via na educação a instância responsável por permitir que isso ocorresse. Era a escolha prematura do sistema educacional britânico que forjava a geração de jovens que teriam uma formação parcial.

${ }^{6}$ MORIN, EDGAR. Ciência com consciência. Rio de Janeiro: Bertand Brasil, 2005.

7 Ainda, segundo Snow (SNOW, C.P. The Two Cultures. Cambridge: Cambridge University Press, 1993, p. 25), o que motivou a grande fragmentação entre as culturas foi o desenvolvimento da sociedade industrial.

8 PINHEIRO, N. A. M.; SILVEIRA, R. M. C. F.; BAZZO, W. A. Ciência, Tecnologia e Sociedade: a relevância do enfoque CTS para o contexto do Ensino Médio. Ciência \& Educação, v. 13, n. 1, p. 71-84, 2007.

${ }^{9}$ AULER, D. Enfoque Ciência-Tecnologia-Sociedade: pressupostos para o contexto brasileiro. Ciência \& Ensino, vol. 1, Número Especial: "Educação em Ciência, Tecnologia, Sociedade e Ambiente", 2007.

10 AULER, D.; BAZZO, W. A. Reflexões para implementação do movimento CTS no contexto educacional brasileiro. Ciência \& Educação, vol.7, n.1, p.1-13, 2001.

11 MEDINA, M.; SANMARTÍN, J. Ciencia, Tecnologia y Sociedad: estudios interdisciplinares en la universidad, en la educación y en la gestión pública. Barcelona: Anthropos, 1990. 
2. Questionar a distinção convencional entre conhecimento teórico e conhecimento prático - assim como sua distribuição social entre 'os que pensam' e 'os que executam' que reflete, por sua vez, um sistema educativo dúbio, que diferencia a educação geral da vocacional.

3. Combater a segmentação do conhecimento, em todos os níveis de educação.

4. Promover uma autêntica democratização do conhecimento científico e tecnológico, de modo que ela não só se difunda, mas que se integre na atividade produtiva das comunidades de maneira crítica.

Desta maneira, a importância de discutir com os alunos os avanços da ciência e tecnologia, suas causas, consequências, os interesses econômicos e políticos, de forma contextualizada, está no fato de que devemos conceber a ciência como fruto da criação humana. Por isso, ela está intimamente ligada à evolução do ser humano, desenvolvendo-se permeada pela ação reflexiva de quem sofre/age as diversas crises inerentes a esse processo de desenvolvimento.

A ideia de levar para sala de aula o debate sobre as relações existentes entre Ciência, Tecnologia e Sociedade, principalmente no ensino médio vem sendo discutida por meio dos Parâmetros Curriculares Nacionais (PCNs). Para isso, precisamos entender a educação que prioriza a discussão a partir da evolução da ciência e da tecnologia num sentido que leve os alunos a compreender sua dimensão social, tanto do ponto de vista dos seus antecedentes sociais quanto de suas consequências sociais e ambientais. Ou seja, é preciso compreendê-la no que diz respeito aos fatores de natureza social, política ou econômica que modulam a mudança científico-tecnológica e, no que concerne às repercussões éticas, ambientais ou culturais dessa mudança.

As experiências realizadas neste âmbito nos levam a iniciativas ligadas às próprias áreas da ciência. Segundo Angotti e Auth ${ }^{12}$, os estudos em ciência e tecnologia têm atribuído importante papel aos aspectos históricos e epistemológicos da ciência e a interdisciplinaridade na alfabetização em ciência e tecnologia. Eles indicam a importância de se explorar os conhecimentos sob um caráter mais abrangente, de forma que se consiga fazer uma reflexão mais ampla, mais crítica. Seria necessário contrastar as visões oficiais presentes nos sistemas de ensino e organizar uma nova fonte de visões alternativas para o mesmo ensino. Isto seria prioritário para a organização de uma imagem de ciência e de tecnologia que possa revelar a dimensão social do desenvolvimento científico e tecnológico, compreendido como um produto resultante de fatores culturais, políticos e econômicos ${ }^{13}$.

Apontamos aqui algumas iniciativas do trabalho com história da ciência e sua interface com a educação. Embora essas iniciativas apareçam em meados dos anos 2000, continuam ainda (pensando que já estamos em 2017...) indicando a mesma forma de ação: a interface da ciência e educação deve se dar sempre a partir da ciência. A revista História da Ciência e Ensino, publicada desde 2010 pela Pontifícia Universidade Católica de São Paulo (PUC), fruto do trabalho de um grupo dedicado aos trabalhos em História da Ciência, traz uma série de estudos apontando para essa relação. Saito ${ }^{14}$ um dos idealizadores da revista, afirma que sua publicação vem para "dar início ao diálogo entre historiadores da ciência e educadores de modo a promover uma maior interação entre História da Ciência e Ensino”. Ainda, segundo Saito (pag. 5), a

12 ANGOTTI, J. A. P.; AUTH, M. A. Ciência e Tecnologia: implicações sociais e o papel da Educação. Ciência \& Educação, v. 7, n. 1, p. 15-27, 2001.

13 PINHEIRO, N. A. M. Educaşão Crítico-Reflexiva para um Ensino Médio Científico-Tecnológico: a contribuição do enfoque CTS para o ensino-aprendizagem do conbecimento matemático. Tese (Doutorado em Educação Científica e Tecnológica). Universidade Federal de Santa Catarina, Florianópolis, 2005.

14 SAITO, F. História da Ciência e ensino: em busca de diálogo entre historiadores e educadores. In História da Ciência e Ensino: construindo interfaces. Ano 1, vol. 1, p. 01-06, 2010. In http://revistas.pucsp.br/index.php/hcensino/article/view/3069/2028, acesso em 12 de abril de 2016. 
revista pretende auxiliar nessa interface pois "do ponto de vista do historiador da ciência, seria somente por meio da abordagem historiográfica atual que a História da Ciência poderia contribuir de maneira mais profícua para o ensino".

Para os autores,

Defendemos a História da Ciência, interdisciplinar por excelência, como elemento necessário à motivação e formação dos futuros professores, permitindo-lhes um maior aprofundamento nos conteúdos disciplinares. Justificamos essa posição por entendermos que conhecer o porquê e o para quê dos fatos têm potencial para transformar a motivação extrínseca em motivação intrínseca, ou seja, o aprendiz não mais estudará a fim de obter recompensas ou de evitar punições externas, mas porque serão atendidas algumas das suas necessidades internas (... $)^{15}$.

Podemos incluir no âmbito de revistas que continuam publicando artigos relacionados à História da Ciência, a revista da Sociedade Brasileira de História da Ciência (SBHC) que ao longo de sua história sempre publicou artigos que defendem a inclusão da história da ciência na escola básica e que, em dezembro de 2014 dedicou um volume exclusivamente para a publicação de diferentes propostas de trabalhos com história da ciência na escola, tais como o de Tatiana Roque que escreveu sobre a história como fundamento no ensino das equações matemáticas,

Objetos matemáticos, como a equação, trazem encapsulados os problemas que ficaram pelo caminho, no processo de sua constituição. Como o ensino parte destes objetos como dados, a história pode ter um papel fundamental em desmascarar seu percurso, exibindo problemas que se encontram por debaixo de sua afirmação peremptória como algo a ser incorporado e resolvi$\mathrm{do}^{16}$.

Observamos ainda que o interesse sobre o tema não para na década de 1990 e vem aumentando de modo notável também na última década. Podemos citar diferentes trabalhos acadêmicos, desde a pesquisa de Gebara ${ }^{17}$, que demonstra a importância da história da ciência no ensino de física, no ensino médio; o importante trabalho de Forato ${ }^{18}$, que defende o uso de história da ciência na educação científica; até a recente proposta de Gandolfi ${ }^{19}$, descrevendo a importância da análise histórica no ensino da disciplina química.

Nossa proposta para esta pesquisa é a de trabalhar com o ensino de história da ciência no currículo escolar do Ensino Médio. Não sob a forma de projeto ou de trabalho esporádico em diferentes disciplinas, mas sim o de usar a área de humanidades - mais especificamente a disciplina de história - para fazer esta relação. Com a visão da ciência e tecnologia o trabalho em sala de aula passaria a ter outra conotação. Além disso, a integração entre humanidades, ciências da natureza e matemática realizada por meio de estudos de história da ciência e tecnologia

${ }^{15}$ FERREIRA, A. M. P.; FERREIRA, M. E. M. P. A História da Ciência na formação de professores. In História da Ciência e Ensino: construindo interfaces. Ano 1, vol. 2, p. 01-13, 2010. In http://revistas.pucsp.br/index.php/hcensino/article/view/2904/2861, acesso em 12 de abril de 2016.

16 ROQUE, T. Desmascarando a equação. A história do ensino da matemática? Revista Brasileira de História da Ciência. v. 7, n. 21, p. 167-185, 2014.

17 GEBARA, M. J. F. O ensino e a aprendizagem de física. 2001.Dissertação (Mestrado em Educação) - Faculdade de Educação, Universidade de Campinas, São Paulo, 2001.

${ }^{18}$ FORATO, T. C. M. A natureza da ciência como saber escolar: um estudo de caso a partir da bistória da luz: 2009. Tese (Doutorado em Educação) - Faculdade de Educação, Universidade de São Paulo, São Paulo, 2009.

${ }^{19}$ GANDOLFI, H.E. A natureza da quimica em fontes históricas do Brasil colonial (1748-1855): contribuições da história da exploração mineral para o ensino da química. 2015. Dissertação (Mestrado em Educação) - Faculdade de Educação, Universidade de Campinas, São Paulo, 2015. 
facilitaria o trabalho de alunos e professores. Atividades desenvolvidas de forma conjunta evitariam a perpetuação da ideia de que a produção de ciência seja considerada algo sagrado e inviolável. Ao contrário, proporcionaria uma nova visão, aquela de que a ciência está sujeita a críticas e a reformulações, como mostra a própria história de sua produção. Dessa forma, aluno e professor reconstroem a estrutura doconhecimento.

Como prática pedagógica, isso significa romper com a concepção tradicional que predomina na escola e promover uma nova forma de entender a produção do saber. É desmitificar o espírito da neutralidade da ciência e encarar sua responsabilidade política. Isso supera a mera repetição do ensino das leis que regem o fenômeno e possibilita refletir sobre o uso político e social que se faz desse saber. Os alunos recebem subsídios para questionar, desenvolver a imaginação e o raciocínio próprio, abandonando o estado de subserviência diante do professor e do conhecimento apresentado em sala de aula.

Portanto, para realizar a implementação de um currículo, no ensino médio, permeado de história da ciência, embasando as práticas das disciplinas das áreas das ciências da natureza e matemática precisamos fazer o percurso histórico do uso destes conceitos na escola, no mundo e principalmente no que diz respeito ao que foi realizado no Brasil. Só a partir do percurso de sua historicidade é que seremos capazes de compreender a necessidade atual de se trabalhar esta questão no ensino médio.

Outro aspecto a ser considerado é o diálogo existente (ou não) entre a universidade, produtora do conhecimento e a escola de ensino médio. Esta questão é fundamental, já que o que se ensina na escola muitas vezes não está sintonia com o que se produz na universidade.

A justificativa para a realização desta reflexão está fundamentada na sugestão de uma reestruturação curricular para o ensino médio ${ }^{20}$. Em tempos de muitas mudanças, a análise realizada através deste artigo torna-se uma importante ferramenta para a modificação das práticas na sala de aula ${ }^{21}$

A proposta de trabalho para essa pesquisa está baseada na ideia da aproximação entre a área de humanidades, mais especificamente a história da área de ciências da natureza na sala de aula do ensino médio. Segundo a primeira versão da Base Nacional Comum Curricular ${ }^{22}$,

No Ensino Médio, com a maior vivência social e maturidade de jovens e adultos, os conceitos de cada componente curricular podem ser aprofundados em suas especificidades

${ }^{20}$ No ano de 2016 foi publicada a $2^{\text {a }}$ versão pelo governo federal a nova Base Curricular Nacional com o objetivo de deixar claro os conhecimentos essenciais aos quais todos os estudantes brasileiros têm o direito de ter acesso e se apropriar durante sua trajetória na Educação Básica (da Educação Infantil até o Ensino Médio). A Base ainda está sendo escrita. Espera-se uma terceira versão para 2017, antes de ser aprovada. Informação disponível em http://basenacionalcomum.mec.gov.br/\#/site/inicio, acesso em 12 de agosto de 2016.

${ }^{21}$ No segundo semestre deste ano, o governo federal apresentou requerimento de urgência na votação da alteração da LDB 9394/96 para alterar a organização curricular do Ensino Médio. "A renovação do Ensino Médio é uma das prioridades do país nos próximos anos. Segundo o atual ministro da Educação, Mendonça Filho, o governo irá trabalhar junto à sua base no Congresso Nacional para priorizar a votação do Projeto de Lei (PL) 6.840/2013, que propõe mudanças importantes nas séries finais do ensino regular"

http://www.brasil.gov.br/educacao/2016/09/projeto-de-lei-propoe-reestruturacao-do-ensino-medio, acesso em 01 de outubro de 2016.

22 A Base Nacional Comum Curricular (BNCC) para o ensino infantil e fundamental (I e II) foi finalizada e publicada em seis de abril de 2017. A BNCC para o ensino médio ainda não foi publicada, em sua versão final. "A base curricular inclui todos os conhecimentos e habilidades que o estudante deve aprender, da Educação Infantil até o nono ano do Ensino Fundamental, e estabelece qual é o conteúdo essencial que deve ser seguido pelas escolas públicas e particulares. A expectativa é que os colégios comecem a adotar a nova base a partir de 2019."

http://g1.globo.com/jornal-hoje/noticia/2017/04/ministerio-da-educacao-define-base-nacionalcomum-curricular-bncc.html, acesso em 12 de maio de 2017. 
temáticas e em seus modelos abstratos, ampliando a leitura do mundo físico e social, o enfrentamento de situações relacionadas às Ciências da Natureza, o desenvolvimento do pensamento crítico e tomadas de decisões mais conscientes e consistentes. Também podem ser aprofundados os modos de pensar e de falar próprios da cultura científica, situando-a entre outras formas de organização do conhecimento, e de compreender os processos históricos e sociais de produção científica.

(...) A cultura científica a ser vivida e incorporada pelos jovens no Ensino Médio advém de uma articulação consistente entre os fundamentos conceituais e sua aplicação em contexto. Ao mesmo tempo em que os/ as estudantes observam fenômenos, formulam hipóteses sobre eles e produzem explicações teóricas, é importante que o conhecimento aprendido repercuta significativamente nos seus contextos de vida. Esse desenvolvimento cognitivo e cultural do/da estudante é pressuposto necessário para atender às demandas formativas para sua atuação como cidadão, para que possa se inserir no mundo do trabalho e da participação social, com consciência de direitos, responsabilidade social e ambiental, autonomia intelectual e princípios éticos, fazendo uso dos modos de pensar e expressar da cultura científica, ao lado da compreensão dos processos sociais e históricos, inclusive os que permitirão a construção de novos conhecimentos científicos ${ }^{23}$.

Geralmente, as disciplinas ligadas às ciências da natureza e matemática são consideradas as de mais complexa compreensão pela maioria dos estudantes. Como já nos referimos anteriormente, são essas as disciplinas as que mais reprovam estudantes. Em minha prática pessoal, tanto na rede pública quanto na rede privada, observei que alunos promovidos (portanto, considerados aptos para cursar a série seguinte, continuavam tendo dificuldade em compreender (e, muitas vezes, efetivamente não compreendiam) conceitos básicos das chamadas "ciências duras". Buscando uma alternativa para superar este problema proponho um trabalho a ser desenvolvido em história da ciência.

Essa proposta por si só não é desconhecida. Como nos referimos anteriormente, existem muitas pesquisas e trabalhos acadêmicos que discutem essa prática. Isto é, a aplicação de um trabalho vinculado à história da ciência proporciona que o estudante consiga desenvolver uma base cognitiva que facilitaria sua compreensão do conceito científico. Significa dizer que o estudo do contexto histórico em que determinado cientista vivia ao desenvolver sua teoria poderia ajudar o aluno a compreender o conceito científico propriamente dito.

Para colocar em prática esse trabalho podemos seguir por dois caminhos, a saber: a) o professor especialista da área da ciência da natureza e matemática faz a contextualização e trabalha especificamente com os conceitos de história da ciência em sua aula (o que é mais comum de ser realizado); b) o professor de história se encarregaria de fazer a contextualização histórica e trabalharia em parceria com o professor de ciência da natureza ou matemática ${ }^{24}$.

Neste artigo optamos pela defesa do segundo modelo. Escolhemos dar foco ao trabalho com história da ciência usando a segunda perspectiva de abordagem já que o professor especialista em ciência da natureza (química, física e biologia) ou mesmo da matemática geralmente tem pouco conhecimento da história de sua própria disciplina ${ }^{25}$. Desta forma, cabe ao professor de história adaptar seu conteúdo para trabalhar conjuntamente com os professores das diferentes áreas da ciência.

23 BRASIL - BNCC, 2016 p. 582-583.

${ }^{24}$ A segunda proposta só seria viável se os professores (humanidades e ciência da natureza) se dispusessem a trabalhar conjuntamente.

25 Ao analisar mais de perto a matriz curricular dos cursos de licenciatura em biologia, química, física e matemática nos cursos oferecidos pela Universidade de São Paulo, Universidade de Campinas, Universidade Estadual Paulista e algumas das universidades federais observamos que existem disciplinas de história da ciência. Geralmente são opcionais, oferecidas a partir da metade do curso. Reiteramos que não é apenas a manutenção de um semestre de uma disciplina "denominada" de história da ciência dentro do curso de graduação que capacitará o futuro professor a trabalhar com a visão da história de sua disciplina na sala de aula. 
Mas, para um entendimento mais adequado desta proposta precisamos vislumbrar, de forma sucinta, a importância do componente curricular história na perspectiva da educação brasileira.

Segundo Nadai ${ }^{26}$, no Brasil, a história surge, como disciplina escolar autônoma, em fins do século XIX, envolvida nos movimentos de laicização social transcorrido naquele período ${ }^{27}$. O contexto nos ajuda a entender a necessidade da oficialização da história. Em meio as tentativas de se organizar e de se justificar a formação das Nações, a história aparece como a genealogia da Nação além de fundamentar a necessidade da mudança para o crescimento. Desta forma, a autonomia concedida ao objeto histórico conseguiu unificar duas tradições do século XVIII, a saber: uma a do discurso enciclopédico que vinha promovendo uma doutrina do progresso $^{28}$ e uma nova elaboração metodológica (isto é, um grupo de técnicas e saberes distintos, cronologias) que remodelou a educação formal (no âmbito do ensino desta nova disciplina), adotando um método científico, característico da concepção positivista, adotando a linguagem das ciências naturais, estabelecendo um novo sentido para a história. "É que a grande mutação do século XIX, e em particular dos anos 1820 e 1830, está aí: a história é a árvore genealógica das nações europeias e da civilização de que são portadoras"29.

No Brasil do final do século XIX a própria escola ocupa esta função. Como nos mostra Carvalho $^{30}$, ela foi, no pensar republicano, o símbolo da implementação da nova ordem (a passagem da monarquia para a república precisava ser marcada) e estratégia fundamental para instalação do progresso.

Neste âmbito, o papel da educação foi hiperdimensionado: tratava-se de transformar os habitantes em povo, de vitalizar o organismo nacional, de construir a nação. Nele se forjava o processo político autoritário: educar era uma obra de moldagem do povo, matéria informe e plasmável, conforme os anseios de Ordem e Progresso de um povo que se auto investia como elite com autoridade para promovê-lo ${ }^{31}$.

Desta forma, credita-se à história importância fundamental neste processo. Encontra-se no seio do processo de laicização de nossa sociedade. Assim os programas e currículos para os trabalhos com história dentro do ambiente escolar buscavam garantir a criação de uma identidade comum, na qual os grupos étnicos formadores desta sociedade haviam convivido harmoniosamente, cooperando com a obra colonizadora e civilizatória dos portugueses. Como consequência dessa visão da história nacional, no espaço escolar o ensino da história reforça a falsa ideia de uma igualdade social e institucionaliza-se uma memória oficial. Com esta estratégia cria-se uma história a ser aprendida em que a memória dos grupos sociais, das classes, das etnias não dominantes não se encontravam identificadas, representadas ou valorizadas.

Esta visão da história como disciplina começa a mudar após a II Grande Guerra em razão da evolução da própria disciplina e também como fim da hegemonia europeia no mundo.

\footnotetext{
26 NADAI, E. "O ensino de história e a pedagogia do cidadão" in PINSKY. J. (org). O ensino de bistória e a criação do fato. Ed. Contexto: SP, 1992.

27 Segundo Silva e Fonseca (2010, p. 60) "No caso específico da disciplina história, a partir do século XIX, identificam-se dezoito programas de Ensino relativos às reformas curriculares entre os anos de 1841 e 1951. Esses programas foram organizados pelo Colégio Pedro II, do Rio de Janeiro, de acordo com as diretrizes das várias reformas curriculares ocorridas naquele período”.

${ }^{28}$ Foram os iluministas num intenso movimento cultural dentro de uma Europa fervilhante de ideias e críticas ao sistema instituído que, pela primeira vez, buscaram conceituar o progresso. Para eles os homens estavam fadados ao progresso, uma onda inexorável que levaria a humanidade a um estágio muito avançado, de bem-estar, de felicidade (AQUINO, G. T. M. Progresso, Tecnologia e Engenharia: um olhar sobre a Faculdade de Engenharia Industrial e a Igreja Católica na construção do Grande ABC (1946-2000). Dissertação (Mestrado em História Social), FFLCH-USP, 2010, p. 28).

${ }^{29}$ FURET, F. A Oficina da História. Lisboa: Gradiva, 1986, p. 135.

30 CARVALHO, M. M. C. A Escola e a República. Ed. Brasiliense: SP, 1989, p.7.

31 idem, p.9.
} 
No Brasil o movimento teve início um pouco mais tarde. Podemos explicá-lo de duas formas: modificações internas do próprio discurso histórico e também por causa das modificações que alteraram a forma e a natureza de nossa escola, principalmente o que chamamos de escola secundária.

Até a década de 1940 o ensino de história realizava-se com o objetivo de criar uma ideia de nação ideal e sem conflitos sociais, econômicos ou étnicos. A partir desta data as classes populares começaram a ter acesso à escola. O Brasil precisava de mão-de-obra treinada para dar continuidade ao seu processo de crescimento econômico, do crescimento da industrialização. Isso tem consequências diretas na educação e, com muita força, no ensino de história. Passamos por uma série de mudanças de base, mas o caráter positivista ainda estava bastante presente nos nossos manuais de história e nas aulas dentro do ambiente escolar.

No final da década de 1980 a educação brasileira passa por uma série de revisões e temos muitos teóricos interessados em analisar a história ensinada em nossas escolas. Muitos congressos, seminários e obras que eram escritas baseadas nesses eventos. As universidades discutiam a qualidade das aulas de história ministradas no país e o caminho pelo qual deveriam se organizar os novos currículos.

Com o fim do regime militar no Brasil (1985) implementa-se uma nova Constituição (1988) o que dá início a uma nova fase na educação brasileira. A questão do debate de um currículo unificado para todo o território nacional é recente (desde 1996, com a instauração dos Parâmetros Curriculares Nacionais), mas ao longo da história do nosso país nota-se que esse debate já existia. Uma grande reforma foi estabelecida pela Lei no. 9.394/96, instituindo uma nova Lei de Diretrizes e Bases (LDB), estabelecendo os Parâmetros Curriculares Nacionais. Esta lei confirma as tendências da afirmação de uma escolaridade básica mais prolongada e a proposta de uma educação profissional mais abrangente e, portanto, para além do adestramento às técnicas de trabalho, afirmando o propósito de estender ao poder público a obrigatoriedade de oferta do ensino médio como direito de cidadania. Os parâmetros que passam a orientar as ofertas educacionais na nova ordem da economia mundial.

É importante notar que o debate de uma educação de âmbito nacional, acompanhada das questões curriculares para a implementação de um currículo unificado para todo o território, sempre esteve presente na história da educação brasileira. As tentativas ao longo do tempo não puderam se concretizar por causa das políticas públicas relativas à educação: num dado momento, o Estado tinha a obrigatoriedade de fornecer a educação pública para os cidadãos, e em outro não. Essas oscilações do dever do Estado frente à educação geraram consequências para nossa educação que perduram até hoje. Os Parâmetros Curriculares Nacionais só se concretizaram graças à redemocratização do país, quando se reabriu o debate em torno da questão da educação pública e das questões curriculares.

Partindo do Parâmetros Curriculares Nacionais de História,

A História enquanto disciplina escolar, ao integrar-se à área de Ciências Humanas e suas Tecnologias, possibilita ampliar estudos sobre as problemáticas contemporâneas, situando-as nas diversas temporalidades, servindo como arcabouço para reflexão sobre possibilidades e/ou necessidades de mudanças e/ou continuidades ${ }^{32}$.

Ainda, segundo o mesmo documento, observa-se que as concepções políticas, sociais e aquelas que aproximam o homem da natureza vêm se modificando e a sociedade tem a necessidade de ficar atenta a estas mudanças. Existe ainda a menção ao avanço científico e tecnoló-

32 BRASIL, PCNH, 2011, p. 20 
gico que teria desempenhado papel prioritário na modificação da vocação do ensino, até do papel da escola. Por estes motivos explicita-se ainda mais a importância de se manter uma escola mais humanizada, "um Ensino Médio de caráter humanista ${ }^{33}$ capaz de impedir a constituição de uma visão apenas utilitária e profissional das disciplinas escolares.

Neste contexto podemos afirmar que a história tem sim o papel de humanizar o ensino em uma sociedade que valoriza mais a tecnologia do que o papel do homem, mas seria bastante interessante que pudéssemos aglutinar as duas visões. Isto é, trazer para a sala de aula uma visão mais humanizada do mundo, mas também mostrar que este mundo inserido na técnica e imbuído de ciência tem uma relação muito íntima com sua própria história. Acredito que com esta visão poderemos trabalhar, dentro do currículo escolar, a história através das mudanças promovidas pelo desenvolvimento da ciência e da tecnologia. Além disso haveria um ganho na apreensão de conceitos embutidos dentro do ensino das ciências e matemática.

Sabe-se que vivemos em uma época de ascensão das técnicas de informação, explicitada, sobretudo pelas mudanças que ocorrem diariamente, desencadeando a modificação de valores, a influência da ciência e da tecnologia. Da mesma forma a educação científica também passa a ser prioritária para a compreensão deste mundo. Observamos também que o ensino das ciências, em geral, delineia-se com uma imagem desconectada desta realidade. Em geral a escola está separada desta realidade utilizando-se de material que poderíamos denominar de ultrapassado; na realidade é a forma de pensar a aula e de passar o conteúdo é que está obsoleta. Como nos mostra Cunha ${ }^{34}$ o material didático (enfatizamos aqui o próprio livro didático) que traz uma imagem puramente empirista da ciência, geralmente cumulativa e operativa. Na maioria dos casos não leva em consideração os aspectos qualitativos como o histórico, sociológico ehumanista.

Por esta e outras razões começaram a aparecer manifestações mais enfáticas em defesa de mudanças no ensino de ciências na escola a partir da década de 1950. O contexto do pósguerra e a importância cada vez maior dada à ciência traz à tona a discussão sobre ciência na escola.

É relevante apontarmos que no ano de 1959, Charles Snow, proferiu sua célebre conferência na Universidade de Cambridge, intitulada "As duas culturas" 35 . É também interessante apontarmos que Snow enxergou na Educação uma forma de conciliação para as "duas culturas"36.

Nas décadas de 1960 e 1970 as manifestações a favor da introdução da história da ciência na educação são pautadas na defesa da mudança de conteúdo desenvolvido no ensino de ciências nas escolas de ensino básico bem como nos cursos de graduação.

A partir da metade da década de 1980 observa-se o início de uma forte campanha internacional para uma maior aproximação entre o ensino de ciência e humanidades - mais particularmente envolvendo história, filosofia e sociologia. No ambiente acadêmico passam a ser veiculados argumentos favoráveis ao estudo de filosofia e história da ciência inseridos nas disciplinas de ciência na escola de ensino básico.

Segundo Matthew ${ }^{37}$ neste período (década de 1980) os americanos detectaram uma

\footnotetext{
33 Grifo do documento.

${ }^{34}$ CUNHA, B. C. O movimento Ciência/Tecnologia/Sociedade (CTS) e o ensino de ciências: condicionantes estruturais. Revista Varia Scientia, v. 6, n. 12, p 121-134, 2006.

35 Sobre a conferência proferida por Snow e suas consequências ver nota 4, p. 17.

36 SNOW, C.P. The Two Cultures. Cambridge: Cambridge University Press, 1993.

${ }^{37}$ MATHEW, M. R. História, Filosofia e Ensino de Ciências: a tendência atual de reaproximação. Caderno Brasileiro de Ensino de Física, v. 12, n. 3, p. 164-214, jan.1995. ISSN 2175-7941. Disponível em:
} 
grande falha na educação científica de seus alunos. Esta situação estava vinculada à formação precária de alunos de graduação em diferentes cursos de ciências o que acarretava uma educação ainda mais precária no ensino básico. A própria Fundação Nacional Americana de Ciências denunciou que os programas dos cursos de graduação em ciências, matemática e tecnologia vigentes no país tiveram grande queda de qualidade. A situação era tão alarmante que não correspondiam mais às necessidades nacionais. Como alternativa para esta situação defendeuse a inserção de história das ciências nos cursos de graduação e na educação básica. Segundo Matthew ${ }^{38}$,

A história, a filosofia e a sociologia da ciência não têm todas as respostas para essa crise, porém possuem algumas delas: podem humanizar as ciências e aproximá-las dos interesses pessoais, éticos, culturais e políticos da comunidade; podem tomar as aulas de ciências mais desafiadoras e reflexivas, permitindo, deste modo, o desenvolvimento do pensamento crítico; podem contribuir para um entendimento mais integral de matéria científica, isto é, podem contribuir para a superação do 'mar de falta de significação' que se diz ter inundado as salas de aula de ciências, onde fórmulas e equações são recitadas sem que muitos cheguem a saber o que significam; podem melhorar a formação do professor auxiliando o desenvolvimento de uma epistemologia da ciência mais rica e mais autêntica, ou seja, de uma maior compreensão da estrutura das ciências bem como do espaço que ocupam no sistema intelectual das coisas.

Como forma de retomar a educação científica de qualidade muitas iniciativas foram realizadas, sempre acompanhadas da sugestão de que o trabalho de ciências deveria estar ligado a história, filosofia e sociologia da ciência. Muitos encontros, conferências e seminários internacionais foram organizados, como nos mostra Matthew ${ }^{39}$.

A realização da primeira conferência internacional sobre 'História, Filosofia, Sociologia e o Ensino de Ciências', na Universidade Estadual da Flórida, em novembro de 1989. O segundo, uma série de conferências patrocinadas pela Sociedade Europeia de Física sobre A História da Física e o seu ensino, realizadas em Pávia - cidade ao sul de Milão (1983), Munique (1986), Paris (1988), e Cambridge (1990). O terceiro, foi a conferência sobre 'História da ciência e o ensino de ciências', realizada na Universidade de Oxford em 1987 com o apoio da Sociedade Britânica de História da Ciência (Shortland \& Warick, 1989). Essas iniciativas geraram cerca de trezentos estudos acadêmicos sobre aquela questão e muito material didático histórica e filosoficamente embasados. Além disso, a Fundação Nacional Americana de Ciência já deu início a dois programas que visam a promover o engajamento de história, filosofia e sociologia ao ensino de ciências nos cursos de primeiro e segundo grau. Alguns programas americanos de formação de professores de ciências tomaram história, filosofia e sociologia obrigatórias e o estado da Flórida vinculou a concessão de licença para o ensino de ciências à conclusão de um curso em HFS.

Dentre estas iniciativas podemos ressaltar a elaboração do Projeto 2061 da Associação Americana para o Progresso da Ciência (AAAS) ${ }^{40}$, além de outras em países como GrãBretanha, Holanda, Dinamarca. Em geral, todas essas ações trazem como estratégia básica a aproximação da ciência com a história, filosofia e sociologia das ciências. Esta ação seria realizada através de uma mudança curricular, com a introdução destas disciplinas no processo de

<https://periodicos.ufsc.br/index.php/fisica/article/view/7084/6555>. Acesso em: 12 nov. 2014. doi:http://dx.doi.org/10.5007/7084

${ }^{38}$ Idem, p. 165.

${ }^{39}$ Idem, p. 166.

40 O Projeto 2061 foi lançado em 1985. É um projeto de longo prazo que, em princípio reuniu uma equipe de especialistas nas diferentes áreas de ciências, matemática, tecnologias para identificar o que seria mais importante para as futuras gerações terem como conhecimento essencial. Dá uma grande definição sobre o que vem a ser alfabetização científica, enfatizando as relações entre as ciências naturais e sociais. (Ver mais em: http://www.project2061.org/esp/Default.htm) 
ensino das escolas básicas.

No Brasil a aproximação entre ensino de ciências e humanidades também passou a ser abordado. A partir de 1950 já se começa a discutir, nos meios acadêmicos, a importância de se trabalhar com a questão de educação científica na educação básica. Ao analisarmos o contexto histórico observamos que a ação é muito pertinente já que passávamos por um período de necessidade de crescimento por causa do avanço da industrialização e da necessidade de se preparar (qualificar) os indivíduos que seriam inseridos nesse processo. É a partir da década de 1970 que que essa realidade começa a tomar forma e apenas nos anos 1980 que, com a renovação do ensino de ciências, passa a se reorientar pelo objetivo de analisar as implicações sociais do desenvolvimento científico e tecnológico.

A partir da década de 1990 aparece com certa relevância no Brasil o movimento CTS (Ciência, Tecnologia e Sociedade). Segundo Strider ${ }^{41}$ esta década deve considerada como marco porque foi nesse período que se desenvolveram as primeiras pesquisas envolvendo esta temática na educação científica. Esta perspectiva mudou a visão do ensino das ciências pois trouxe uma preocupação com os conhecimentos da ciência e tecnologia na aplicação de sua sociedade. Apesar da tendência ter grande repercussão nos meios acadêmicos a maioria dos professores não consegue colocá-la em prática.

Foi na década de 1990 com a publicação dos Parâmetros Curriculares Nacionais que a temática do trabalho integrado (com grande ênfase à mediação do ensino-aprendizagem pela história da ciência) tornou-se palpável.

De forma geral observamos que o ensino das ciências dentro do âmbito escolar foi desenvolvido no Brasil após reformas e leis. Destacamos que sempre foi realizada baseando-se em dois modelos: ciências integradas e ciências fragmentada. Embora os Parâmetros Curriculares apontarem o modelo integrado como modelo oficial sabemos que as escolas têm optado pelo segundo modelo.

Mais recentemente, como já mencionamos, a Nova Base Curricular Nacional, cita a importância do entendimento das ciências da natureza através do viés histórico para que possa ser compreendido como parte de nossa vida cotidiana. Portanto o saber histórico deve estar permeado em todos os aspectos da educação formal ${ }^{42}$.

Como já citado, nosso estudo se debruça sobre a tentativa de promover o ensino integrado das ciências e utilizando como elemento sintetizador a história da ciência. Mais do que isso, utiliza a disciplina de história para promover a integração.

Portanto é claro que não podemos dizer que a história da ciência, no Brasil foi introduzida nos currículos brasileiros de forma oficial. Temos presenciado algumas mudanças, muitas vezes relacionadas as necessidades dos professores ou de uma nova forma de enxergar ciência e ensino. No fim da década de 1990, o currículo para o ensino médio ganhou novos contornos, tornando-se mais integrado, mais interdisciplinar, mais coerente com a realidade dos alunos e mais sensível aos avanços científicos e tecnológicos da atualidade. Presenciamos algum avanço, mas inúmeras dificuldades e dúvidas tiveram origem no fato de muitas das reformas curriculares ocorridas a partir da segunda metade do século XX objetivaram uma reorientação de habilidades e competências, mas não definirem propriamente mudanças específicas no conteúdo do ensino de ciências. Isso dificultou o trabalho dos professores desta área do conhecimento.

${ }^{41}$ STRIEDER, R. B. Abordagens CTS na Educação Científica no Brasil: Sentidos e Perspectivas. Tese de Doutorado. São Paulo: IF/IQ/IB/FE USP, 2012.

42 Vale acrescentar que a nova Base Nacional Comum Curricular não menciona (até a última versão) a necessidade de trabalho com história da ciência, deixando de lado essa peculiaridade da história. Em nossa concepção isto acontece, pois, a área da ciência da natureza assume a responsabilidade de tratar dessa interação (ciência e história). Acreditamos que essa seja uma visão equivocada. 
Os Parâmetros Curriculares deveriam esclarecer e orientar a produção de material para destacar a importância da articulação entre as áreas do conhecimento e a contextualização histórica e cultural. Contudo aquilo que se estruturou para a modificação dos cursos de ciência no ensino médio não apresentou mudança imediata. Uma causa que também deve ser considerada foi a forma genérica como esta mudança foi estruturada e veiculada a partir dos próprios Parâmetros Curriculares.

As tentativas de estabelecer novos currículos nas escolas de ensino básico e integrar a história da ciência no currículo regular ou mesmo ser introduzida na sala de aula (uma tendência nas aulas dos componentes curriculares relacionados à Ciência da Natureza) vem crescendo desde então. Essa realidade fica mais palpável quando examinamos as tentativas de introdução de história da ciência nos cursos de formação/graduação e no lançamento de material especializado, ou mesmo na criação de cursos de pós-graduação com a criação de linhas de pesquisa na área de História da Ciência, tais como a USP, a PUC-SP, a UFMG, a UFBA, a UERJ e a UFABC. Muitas dissertações e teses foram defendidas, nos últimos quinze anos com o objetivo de aproximar a história da ciência do ensino de ciência ou de articular uma formação mais completa para professores, de modo que estes possam se fazer uso dessa linha de trabalho em suas salas de aula.

Essa tendência vem se espalhando cada vez mais. No volume especial da Revista Brasileira de História da Ciência (SBHC), dedicado inteiramente ao Ensino e História da Ciência (Volume 7, n. 2, jul/dez, 2014), nos chama a atenção para um fato importante,

(...) a presença de uma questão no vestibular da Fuvest (Fundação Universitária para o vestibular, instituição autônoma) abordando, de certo modo, um enfoque contextualizado para História da Ciência. A menção a nomes de personagens da história das ciências relacionados a leis e conceitos ou experimentos não é rara, em diversos vestibulares, mas, em geral, esse enfoque se restringe a 'cobrar' os conceitos científicos como aceitos atualmente, e, o conteúdo histórico, propriamente dito, tem um papel mais ilustrativo do que reflexivo e não interfere na resolução desses exercícios.

A justificativa usada para essa afirmação é que a história da ciência, a partir de uma visão crítica, aparece no maior exame vestibular brasileiro, o que, na análise dos pesquisadores, pode ser visto como uma tendência atual. Essa análise nos interessa, pois, partindo da argumentação de muitos acadêmicos e de professores de ensino médio que se interessam em trabalhar o tema existe um obstáculo descrito por todos: o vestibular. O maior vilão da história é o exame pois é ele que dita a seleção de conteúdos que devem ou não ser abordados durante o curso.

Para Martins, essa seria uma questão relevante,

Se a HFC é - quase - uma unanimidade, porque não a vemos contemplada nas salas de aula do ensino médio e em livros didáticos? A resposta é, certamente, simples: não é fácil fazer. Nossos dados reforçam a ideia de que há um abismo entre o valor atribuído à HFC e a sua utilização, com qualidade, como conteúdo e estratégia didática nas salas de aula do nível médio.

Mas, voltamos à reflexão de Forato, Guerra e Braga ${ }^{43}$,

Será que a presença de um enfoque histórico mais contextualizado, ainda que adequadamente tímido poderia ir substituindo as abordagens anacrônica ou até ingênuas, em geral presentes nos exames vestibulares? Tais enfoques poderiam fomentar discussões históricas nas aulas da

43 Op. Citado, p. 137. 
Escola Básica? Caso essa tendência seja consolidada, estariam as Escolas Básicas, seus professores, os formadores desses professores, os materiais didáticos e a própria cultura escolar preparados para tal empreendimento?

O que podemos perceber é que, aos poucos, a preocupação em aproximar a escola básica do que se produz na universidade se faz cada vez mais presente. E essa aproximação busca fazer com que aquilo que entra na escola possa contribuir para a construção de um pensamento crítico e reflexivo sobre a ciência, uma ideia de ciência historicamente construída, que seja reflexo de um contexto e não apenas de um grupo ou de um indivíduo. Desta forma, concordamos com Forato, Guerra e Braga ${ }^{44}$ quando afirmam que,

Para que a presença da História da Ciência se torne amplamente utilizada na Escola Básica, será necessário realizar mais do que produção de materiais didáticos, recomendação de episódios históricos para o ensino, propostas didáticas e investimento na formação de professores. É necessário criar mecanismos para que a produção de conhecimento realizado pela comunidade efetivamente adentre os muros escolares.

As pesquisas e práticas usando história da ciência se estendem para as mais diferentes áreas da ciência. A ciência, desta forma, pode ser compreendida como o resultado de um processo contínuo.

Discutir em sala de aula Ciência como resultado de um processo de construção humano, pode levar o estudante a uma compreensão mais ampla acerca de superação de uma teoria e a acomodação de outra. O caso das teorias apresentadas para a natureza da luz demonstra que nem sempre o processo de superação de uma teoria tem relação direta com os argumentos científicos apresentados pela mesma, como é possível observar através da dificuldade encontrada para a consolidação de uma teoria ondulatória enquanto a imagem científica de Newton ainda possuía grande influência. Levar o aluno a refletir acerca deste processo fará com que ele compreenda as mudanças de paradigma que ocorreram também na ciência atual ${ }^{45}$.

Apontando para a ciência que deve ser contextualizada, Bagdonas, Zanetic e Gurgel ${ }^{46}$ partem da produção de um jogo didático para apresentar conteúdo relativo à cosmologia, ressaltando as controvérsias inseridas nesse debate. Para os pesquisadores, através de uma atividade lúdica incorporada às aulas encontra-se temas muito relevantes para o debate em sala, desde aspectos culturais, passando por aspectos sociais, políticos e crenças religiosas, em relação ao desenvolvimento da ciência, em épocas e regiões diferentes. Segundo os mesmos pesquisadores,

(...) consideramos a realização de discussões sobre aspectos controversos da ciência essenciais para formar cidadãos críticos, conhecedores da riqueza da construção do conhecimento científico e, ao mesmo tempo, conscientes dos limites da autoridade científica, capacitados para contestar de maneira sensata e equilibrada as afirmações emitidas por especialistas sobre que tipo de sociedade que queremos no futuro ${ }^{47}$.

\footnotetext{
44 Op. Citado, p. 141.

${ }^{45}$ BRITO, N. B.; REIS, U.V.; TALON, I. L. M.; REIS, J. C. O. História da física no século XIX: discutindo a natureza da ciência e suas implicações no ensino de física em sala de aula. Revista Brasileira de História da Ciência. v. 7, n. 21, p. 214-231, 2014, p.227.

46 BAGDONAS, A.; ZANETIC, J.; GURGEL, I. Controvérsias sobre a natureza da ciência como enfoque curricular para o ensino de física: o ensino da história da cosmologia por meio de um jogo didático. Revista Brasileira de História da Ciência. vol. 7, n. 21, p. 242-260, 2014.

47 Idem, p. 257.
} 
Portanto, a contextualização serve também para trabalhar as controvérsias que existem em todos os processos de desenvolvimento da ciência e através das controvérsias constrói-se um conhecimento livre da mitificação.

Outro ponto bastante pertinente que preocupa pesquisadores da história da ciência é a produção de material didático. Os livros didáticos disponíveis apresentam conteúdos insuficiente ou, muitas vezes simplistas, quando se trata de conteúdo específico de história da ciência. Vidal e Porto ${ }^{48}$, através de uma pesquisa realizada com livros didáticos de química (coleções que foram aprovadas pelos Programa Nacional do Livro Didático para o Ensino Médio PNLEM de 2007) concluiu, entre outros aspectos, que na maioria das vezes esses livros retiram a dimensão humana de seus personagens, muitas vezes o cientista aparece como uma pessoa genial - dotado de inteligência fora do comum - a informação histórica apresentada geralmente é superficial e, em geral, prevalece a separação entre conteúdo histórico e conteúdo químico. Isso não poderia acontecer e dificulta o trabalho do professor que acredita na importância dessa abordagem, principalmente no ensino médio.

Nessa mesma linha de análise, Ferreira e Peduzzi ${ }^{49}$, buscando resolver uma parte desta questão, acreditam que uma forma de resolver o problema está na produção de materiais didáticos mais adequados para trabalho com a formação de professores. Neste caso, o caminho encontrado foi a produção um texto tratando da questão do atomismo (muito importante para o ensino de química). O texto deveria ser utilizado na formação de professores (cursos de licenciatura) e em cursos de reciclagem para formação de professores que estão já em sala de aula. Segundo as pesquisadoras,

O texto representa uma tentativa de oferecer ao professor um material alternativo para o ensino do atomismo. Nesse sentido vai ao encontro do que recomendam os documentos oficiais e à pesquisa em ensino de ciência, quanto a preencher lacunas ainda grande no que se refere à disponibilidade de materiais relativos ao tema e fundamentos histórica e epistemologicamente ${ }^{50}$.

Silva e Aires ${ }^{51}$ continuam essa análise e acreditam que o material didático deva ser reformulado,

(...) defendemos que a apresentação dos episódios associados ao processo de construção da Teoria Celular tenha um embasamento histórico rigoroso, com o objetivo de, justamente evitar que se incorra em visões simplistas sobre a ciência, fato não raro observado em muitos dos livros didáticos utilizados em nossas escolas. Nesse sentido, consideramos que a História da Ciência tem muito a contribuir para a construção do texto do livro didático e para a formação do professor dessa área, dado o desafio de entendimento dos processos de construção da ciência e não apenas seus produtos. Sendo assim, seria muito enriquecedor para a educação em ciências/biologia que os autores de livros didáticos levassem em consideração estudos históricofilosóficos dos conteúdos, incluíssem contribuições desses estudos no desenvolvimento destes e estivessem atentos para a fidedignidade das informações na elaboração dos textos que contemplam conteúdo da História da Ciência. Outra sugestão seria a instituição de parcerias entre os autores desses livros e historiadores da ciência, a fim de que se garanta o equilíbrio entre os conteúdos específicos da disciplina, uma linguagem acessível e adequada aos estudantes, sem minimizar os aspectos históricos ocorridos ao longo do processo de construção da ciência.

\footnotetext{
${ }^{48}$ VIDAL, P. H. O.; PORTO, P. A. A História da Ciência nos livros didáticos de química do PNLEM 2007. Ciência \& Educação, v. 18, n. 2, p. 291-308, 2012.

49 FERREIRA, L. M.; PEDUZZI, L. O. Q. Uma proposta textual frente a problemas referentes à história do átomo no ensino da química. Revista Brasileira de História da Ciência. v. 7, n. 21, p. 261-277, 2014.

${ }^{50}$ Idem, p. 227.

51 SILVA, E. C. C.; AIRES, J. A. Panorama histórico da Teoria Celular. História da Ciência e Ensino construindo interfaces. PUC, SP, v. 14, p 01-18, 2016, p. 17.
} 
De qualquer forma, temos muitas sugestões de trabalho que apresentam medidas semelhantes. Outro fator a ser considerado e muito mencionado é a questão da formação dos professores. Lorencini e Hidalgo ${ }^{52}$ afirmam que as atividades relacionadas ao ensino da ciência devem levar em consideração as variáveis que existem e fazem parte do próprio conhecimento científico, fugindo assim das práticas tradicionais em que a apresentação do conceito sobressai em relação do motivo e da forma com o qual se insere no contexto científico. Para que isso aconteça, é necessário que exista justamente uma preocupação importante com a formação dos próprios professores.

Para tanto, parece-nos imprescindível que já na formação inicial de professores essas reflexões sejam suscitadas e, além delas, sejam possibilitados momentos de inserção prática destas atividades, de modo que os professores em formação tenham uma base comparativa e de apoio quando adentrarem no mercado de trabalho e iniciarem suas atividades docentes ${ }^{53}$.

Mesmo após tantas tentativas de mudanças, a ciência ainda é vista pelos alunos como um conjunto de dogmas resultante de processos de observação e desvinculada do contexto social. Isso é resultado da visão que o próprio professor traz e que não mudou ao longo de sua formação. Assim, a ciência continua sendo vista como uma atividade superior que só pode ser praticada por indivíduos intelectualmente muito "superiores". Desta forma, praticamente afasta a participação daqueles interessados na produção da ciência, já que tal atividade estaria reservada apenas aos "gênios".

De fato, o que ocorre é que o professor internaliza mitos durante sua formação, transmitindo-os para as crianças, as quais crescem com estes mitos e os transmitem para outros, em um processo contínuo. O professor, ao projetar uma imagem de ciência como produto acabado, e não como um processo que envolve seres humanos e contextos, acaba por criar/reforçar a imagem da ciência enquanto atividade neutra, imparcial e superior ${ }^{54}$.

Sabemos que para que este quadro se transforme precisamos mudar a percepção destes professores para que mudem seu estilo de ensinar. A história da ciência poderia então ser utilizada para modificar a formação de conhecimento a partir da ideia de que ciência é uma atividade humana. Ela deve ser entendida como algo que é produzido por seres humanos inseridos num contexto histórico e que pode atender as mais diferentes aspirações. Portanto não é algo intocável e sim bem palpável e determinada por diferentes necessidades.

Acreditamos que a inserção de história da ciência no ensino médio pode ser importante para a mudança desta realidade. As relações entre ciência e cientista, contexto e pesquisa seriam determinantes para a formação de nossos estudantes, tornando-se essenciais para a formação de um indivíduo crítico que saiba avaliar corretamente as implicações sociais do uso da ciência e da tecnologia.

Mais do que isso, o trabalho desenvolvido com história da ciência pode ser determinante para explicar a relação entre a produção de ciência, propriamente dita e o contexto histórico em que foi produzida. Desta forma, a historicidade da ciência pode propiciar a compreensão crítica do pensamento científico contemporâneo, demonstrando seu caráter histórico e a mobilidade dos processos e métodos de sua produção.

\footnotetext{
52 LORENCINI, A.; HIDALGO, M. R. Reflexões sobre a inserção da História e Filosofia da Ciência no Ensino de Ciências. Revista História da Ciência e Ensino: construindo interfaces, SP, v. 14, p. 19-38, 2016.

53 Idem, p. 37.

${ }^{54}$ SILVA, C. P.; FIGUEIRÔA, S.F.M.; NEWERLA,V. B.; MENDES, M.I.P. Subsídios para o uso da história das Ciências no ensino: exemplos extraídos das geociências. Ciência \& Educação. v. 14, n. 3, pp 497-517, 2008, p. 500.
} 
Neste sentido, a história das ciências deve revelar: a interdependência de fatores científicos e extracientíficos; a interferência de políticas gerais ou específicas no direcionamento de linhas e / ou no estabelecimento de prioridades de pesquisa; a relação inextricável e dinâmica entre o saber técnico-científico e os diferentes contextos culturais entre outros ${ }^{55}$.

Assim, tentaremos formar cidadãos que tenham consciência sobre o funcionamento da investigação científica e sua apropriação evitando que a transmissão dogmática sobre estes conhecimentos seja perpetuada.

Acreditamos ainda que a parceria entre os professores de história e os das ciências da natureza poderia ser benéfica nesse quesito. Julgamos que essa aproximação seja a forma mais viável de se produzir estudantes que enxergam a ciência como produção humana e que essa produção, permeada de conflitos, possa trazer consigo todas as peculiaridades do contexto em que se desenvolve.

Acreditamos que neste momento, em que a a escola básica brasileira, em especial o ensino médio, estão em fase de mudança este pode ser um caminho a ser trilhado, já que deveremos observar mais uma fase de intensas mudanças na estrutura curricular.

55 Idem, p. 514. 